\title{
Complete Pathologic Response in Advanced Primary Gastric Signet-Ring Cell Carcinoma: A Case Report
}

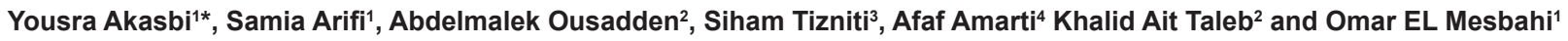

${ }^{1}$ Medical Oncology unit, Hassan II University Hospital, Fez, Morocco

${ }^{2}$ Surgery Department, Hassan II University Hospital, Fez, Morocco

${ }^{3}$ Radiology Department, Hassan II University Hospital, Fez, Morocco

${ }^{4}$ Pathology Department, Hassan II University Hospital, Fez, Morocco

\section{Abstract}

Background: Gastric signet ring cell carcinoma (SRC) is a poorly differentiated adenocarcinoma in which the tumour cells invade singly or in small groups.

The incidence of SRC has been reported in china as $13.9 \%$ (662 patients of 4,759 ) [1]. It is reported to occur more frequent among women and young patients.

A regimen of epirubicin, cisplatin, and infused fluorouracil (ECF) improves survival among patients with incurable locally advanced or metastatic gastric adenocarcinoma.

Case presentation: A 38-year-old female presented with a 3 weeks history of epigastralgia. Her medical history was unremarkable. The endoscopic findings of the stomach revealed an infiltrative lesion, which the guided biopsy yielded a positive pathologic diagnosis of signet ring cell carcinoma. Diagnostic imaging with an abdominal computed tomography (CT) scan revealed a gastric thickening, with lymph nodes. Induction chemotherapy was recommended, based on 6 cycles of ECX (Epirubicin $50 \mathrm{mg} / \mathrm{m}^{2}$, Cisplatin $60 \mathrm{mg} / \mathrm{m}^{2}$, Capecitabine $625 \mathrm{mg} / \mathrm{m}^{2}$ ). The total gastrectomy specimen showed a pathological complete response.

The patient, who is always followed in consultation, is in complete remission 19 months after the diagnosis.

Conclusion: SRC is a distinctive histological type of gastric cancer. The ECX or EOX (epirubicin, oxaliplatine, capecitabine) remains the standard treatment of advanced primary gastric signet-ring cell carcinoma.

Our case illustrates a complete pathologic response to ECX, which confirmed the effectiveness of this protocol on this histology.

Keywords: Gastric signet ring cell carcinoma, ECX, complete pathologic response

Abbreviations: CT: Computed Tomography; ECF: Epirubicin, Cisplatin, and infused Fluorouracil; ECX: Epirubicin, Cisplatin, Capecitabine, EOX: Epirubicin, Oxaliplatine, Xeloda; FAMTX: Fluorouracil, Doxorubicin and Methotrexate; SRC: Signet Ring cell Carcinoma; UICC: Union International Contra la Cancrum; WHO: World Health Organization

\section{Background}

Signet ring cell carcinoma (SRC) is a histological entity based on the microscopic characteristics, not on biological behavior. The clinicopathological characteristics and prognosis in patients with SRC carcinoma of the stomach are still controversial.

The incidence of SRC has been reported in china as 13.9\% (662 patients of 4,759$)$ [1]. It is reported to occur more frequent among women and young patients.

A regimen of epirubicin, cisplatin, and infused fluorouracil (ECF) improves survival among patients with incurable locally advanced or metastatic gastric adenocarcinoma. Therefore, the present case illustrates a complete pathologic response to Epirubicin, Cisplatin and Capecitabine (ECX) in patient presented a metastatic gastric signetring cell carcinoma.

\section{Case Presentation}

A 38-year-old female presented with a 3 weeks history of epigastralgia. Her medical history was unremarkable.
The endoscopic findings of the stomach revealed an infiltrative lesion, which the guided biopsy yielded a positive pathologic diagnosis of signet ring cell carcinoma.

Diagnostic imaging with abdominal computed tomography (CT) scan revealed a gastric thickening, with lymph nodes (Figure 1).

Induction chemotherapy was recommended, based on 3 cycles of ECX (Epirubicine $50 \mathrm{mg} / \mathrm{m}^{2}$, Cisplatine $60 \mathrm{mg} / \mathrm{m}^{2}$, Capecitabine 625 $\mathrm{mg} / \mathrm{m}^{2}$ ). Examination after this treatment showed remarkable reduction of tumor volume in the primary lesion and lymph nodes, which was defined as a partial response (PR) in abdominal CT scan (Figure 2). After 3 others cycles of ECX. The patient underwent total gastrectomy with lymph node dissection (D1, 5). The postoperative course was uneventful without surgical complications. At this time, no gastric cancer cells were detected in the resected specimen, including the

*Corresponding author: Yousra Akasbi, Medical Oncology unit, Hassan II University Hospital, Fez, Morocco, Tel : +212667624156; E-mail: you.yous@ $\underline{\text { hotmail.fr }}$

Received December 28, 2010; Accepted February 17, 2011; Published February 21, 2011

Citation: Akasbi Y, Arifi S, Ousadden A, Tizniti S, Amarti A, et al. (2011) Complete Pathologic Response in Advanced Primary Gastric Signet-Ring Cell Carcinoma: A Case Report. J Cancer Sci Ther 3: 076-078. doi:10.4172/1948-5956.1000062

Copyright: ( 2011 Akasbi Y, et al. This is an open-access article distributed under the terms of the Creative Commons Attribution License, which permits unrestricted use, distribution, and reproduction in any medium, provided the original author and source are credited. 
primary lesion and lymph nodes, confirming a pathological complete response.Thus, this regimen described here may be a potent tool to control metastatic gastric carcinoma.

The patient, who is always followed in consultation, is in complete remission 19 months after the diagnosis.

\section{Discussion}

According to World Health Organization (WHO) classification, SRC is a histological type, primarily based on the microscopic characteristics of the tumor but not on the biologic behavior [2]. SRC has been classified as "diffuse type" by Lauren [3], "infiltrative type" by Ming [4], and "undifferentiated type" by Sugano et al. [5]. To establish a scale of tumor aggressiveness related to prognosis, the WHO [1] and the Union for International cancer control (UICC) [6] adapted a grading system in which SRC has been classified as high grade.

The histogenesis of a signet ring cell component is unclear. Signet ring cells are an intermediate form of squamous and adenocarcinoma cell or a glandular or mucin-secreting component arising in a squamous cell carcinoma as a result of field carcinogenesis, which involves both the covering squamous epithelium and the mucous gland [7].

Signet ring cells can often be confused with benign histiocytes when they show bland nuclei and are separated individually. In these circumstances, histochemical and immunohistochemical staining, such

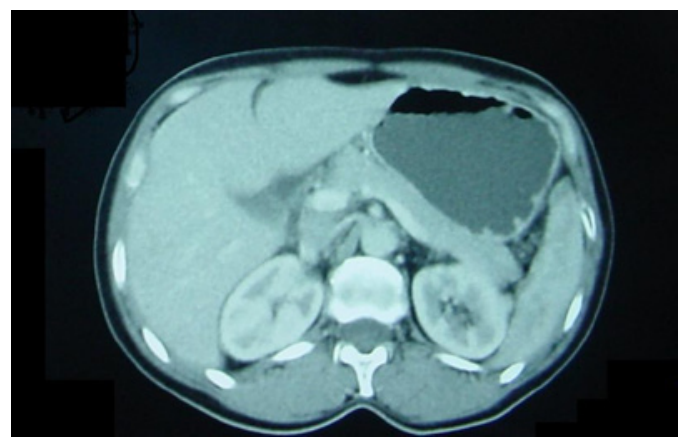

Figure 1: The baseline abdominal computed tomography scan.

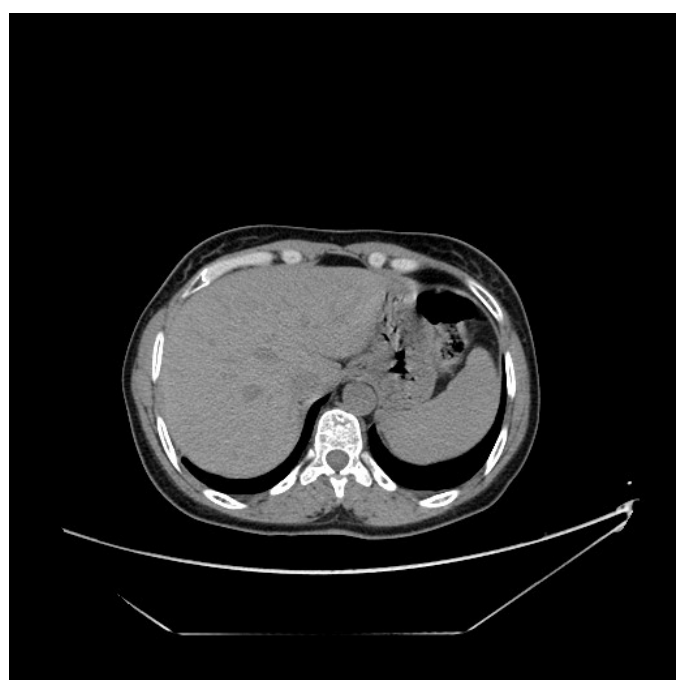

Figure 2: Abdominal computed tomography scan after 6 cycles of chemotherapy. as mucicarmine and cytokeratin, can be useful because histiocytes are negative for these staining [8]. Although there have been studies of the clinicopathologic characteristics including prognosis of SRC, the results were not consistent.

Advanced gastric carcinoma with SRC is characterized by the potential to infiltrate the gastric wall diffusely, and a higher rate of peritoneal dissemination than non-SRC $[9,10]$. It showed a rate of lymph node metastasis similar to or higher than other types of gastric carcinoma [7,9], unlike advanced cancer, early gastric carcinoma with SRC has a significantly lower lymph node metastasis rate than other histology [11].

The outcome among patients with gastric cancer is determined by the stage of the disease at presentation. Localized disease, limited to the mucosa and submucosa, is best treated surgically and has a five-year survival rate of 70 to 95 percent $[12,13]$. Once tumor cells have spread through the submucosa, the risk of lymph-node metastases increases and the likelihood of prolonged disease free survival decreases.

Western surgical and population-based series show that most patients present with a tumor that has penetrated the submucosa; they have a five-year survival rate of 20 to 30 percent [14]. In Japan, extended surgery prolongs survival in such cases, even in the presence of lymphnode metastases [3], but this effect has not been reproduced in Western trials $[15,16]$.

The regimen of ECF, which was developed in the late 1980's, achieves response rates between 49 percent and 56 percent in randomized trials of the treatment of locally advanced gastric cancer $[17,18]$. As compared with a regimen of fluorouracil, doxorubicin, and methotrexate (FAMTX), the ECF regimen improves survival and response rates among patients with advanced esophagogastric cancer $[17,19]$, and the side-effect profile is acceptable. These results have not been improved by substituting mitomycin for epirubicin [11]. A recent meta-analysis found that in advanced disease, epirubicin and cisplatin contribute independently to the efficacy of combination chemotherapy [20].

The MAGIC trial determined that a regimen of ECF given before and after radical surgery improves the outcomes of operable gastric cancer. The potential benefits of administering ECF preoperatively was as follows : increasing the likelihood of curative resection by downstaging the tumor, eliminating micrometastases, rapidly improving tumor-related symptoms, and determining whether the tumor is sensitive to the chemotherapy. The primary end point of this trial was overall survival; secondary end points were progression-free survival, surgical and pathological assessments of down-staging (i.e., tumor diameter, tumor stage, and nodal status), the assessments by the surgeons about whether the surgery was curative, and quality of life, but the pathologic complete response was not evaluated [21].

REAL-2 randomized multicenter phase III study showed that Capécitabine is as effective as fluorouracil in patients with previously untreated advanced esophagogastric cancer [22].

To our knowledge, no study has focused on induction chemotherapy of metastatic SRC, and the incidence of pathologic complete response for gastric cancer and especially for SRC. In consequence, we disposed a few treatment strategies specific to this histology, while newly developed treatment modalities have been introduced for gastric adenocarcinoma.

After a wide study of the medical literature, we found one case of pathologic complete response after chemoradiation in patient with advanced gastric cancer [23]. 
In highly advanced gastric cancer with lymph node metastases, surgery may remove visible tumor masses but microscopic cancer cells may still exist in the blood, lymphatic system or peritoneal cavity. Resulting in local recurrence, distant metastases, or peritoneal dissemination after macroscopically curative surgery.

In the present case, a histological examination of the resected specimen showed no detectable cancer cells. Therefore, we believe that induction chemotherapy based on ECX, eradicated both the primary tumor and all the metastases in this patient. These encouraging results suggest that this regimen is an effective strategy, for the treatment of metastatic gastric signet ring cell carcinoma. Given the generally poor prognosis of these patients, our regimen should be further evaluated as induction chemotherapy to determine its efficacy and toxicity in a larger patient population.

\section{Conclusion}

SRC was a distinctive histological type of gastric cancer. The ECX or EOX (epirubicin, oxaliplatine, Capecitabine) remains the standard treatment of advanced Primary gastric signet-ring cell carcinoma.

Our case illustrates a complete pathologic response to ECX, which confirmed the effectiveness of this protocol on this histology.

\section{Consent}

Written informed consent was obtained from the patient for publication of this case report and accompanying images. A copy of the written consent is available for review By the Editor-in-Chief of this journal.

\section{Competing Interests}

The authors declare that they have no competing interests.

\section{Author's Contribution}

$\mathrm{AH}$ participated in the treatment of the patient, collection of case details, literature search and drafted the manuscript. MN, KS, and YM participated in the treatment of the patient and data collection, and helped to revise the manuscript. All authors have read and approved the final manuscript.

\section{References}

1. Li C, Kim S, Lai JF, Hyung WJ, Choi WH, et al. (2007) Advanced gastric carcinoma with signet ring cell histology. Oncology 72: 64-68.

2. Watanabe $H$, Jass JR, Sobin LH. Histological typing of esophageal and gastric tumors. Who international histological classification of tumors. 2nd ed. Berlin: springer-verlag, 1990.

3. Lauren P (1965) The two histological main types of gastric carcinoma: diffuse and so-called intestinal-type carcinoma. An attempt at a histo-clinical classification. Acta pathol microbial scand 64: 31-49.

4. Ming SC (1977) Gastric carcinoma: A pathobiological classification. Cancer 39: $2475-2485$.

5. Nakamura K, Sugano H, Yakagi K (1968) Carcinoma of the stomach in incipient phase: its histogenesis and histological appearances. Gann 59: 251-258.

6. Sobin LH, Wittekind C. International union against cancer (UICCuicc). TNM classification of malignant tumors. 5th ed. New York: Wiley-Liss, 1997:59-62.

7. Matsuki A, Nishimaki T, Suzuki T, Kanda T, Hatakeyama K (1999) Esophageal mucoepidermoid carcinoma containing signet-ring cells: three case reports and a literature review. J Surg Oncol 71: 54-57.

8. Kwon MS, Ko SO, Cho NP, Kim OH, Shin HK, et al. (2006) Gastric signet-ring cell adenocarcinoma metastatic to the gingiva: a case report. Oral Surg Oral Med Oral Pathol Oral Radiol Endod 102: 62-66.

9. Yamashiro K, Suzuki H, Nagayo T (1977) Electron microscopic study of signetring cells in diffuse carcinoma of the human stomach. Virchows Arch A Pathol Ana Histol 374: 275-284

10. Kubota K, Yamada S, Ito M, Nakamura W, Nagayo T (1977) Cytoplasmic leucine naphthylamidase activity expressed in signet- ring cell carcinoma of the stomach. J Natl Cancer Inst 59: 1599-1604.
11. Hyung WJ, Noh SH, Lee JH, Huh JJ, Lah KH, et al. (2002) Early gastric carcinoma with signet ring cell histology. Cancer 94: 78-83.

12. Sue-Ling HM, Johnston D, Martin IG, Dixon MF, Lansdown MR, et al. (1993) Gastric cancer: a curable disease in Britain. BMJ 307: 591-596.

13. Sasako M, Sano T, Katai H, Maruyama K. Radical surgery. In: Sugimura T, Sasako M, eds. Gastric cancer. Oxford, England: Oxford University Press, 1997:223-48.

14. Siewert JR, Bottcher K, Roder JD, Busch R, Hermanek P, et al. (1993) Prognostic relevance of systematic lymph node dissection in gastric carcinoma. German Gastric Carcinoma Study Group. Br J Surg 80:1015-1018.

15. Hartgrink $\mathrm{HH}$, van de Velde $\mathrm{CJ}$, Putter $\mathrm{H}$, Bonenkamp JJ, Klein Kranenbarg E, et al. (2004) Extended lymph node dissection for gastric cancer: who may benefit? Final results of the randomized Dutch gastric cancer group trial. J Clin Oncol 22: 2069-2077.

16. Mc Culloch P, Nita ME, Kazi H, Gama- Rodrigues J (2004) Extended versus limited lymph nodes dissection technique for adenocarcinoma of the stomach. Cochrane Database Syst Rev 4: CD001964.

17. Webb A, Cunningham D, Scarffe JH, Harper P, Norman A, et al. (1997) Randomized trial comparing epirubicin, cisplatin, and fluorouracil versus fluorouracil, doxorubicin, and methotrexate in advanced esophagogastric cancer. J Clin Oncol 15: 261-267.

18. Ross P, Nicolson M, Cunningham D, Valle J, Seymour M, et al. (2002) Prospective randomized trial comparing mitomycin, cisplatin, and protracted venous-infusion fluorouracil (PVI 5-FU) with epirubicin, cisplatin, and PVI 5-FU in advanced esophagogastric cancer. J Clin Oncol 20: 1996-2004.

19. Waters JS, Norman A, Cunningham D, Scarffe JH, Webb A, et al. (1999) Long-term survival after epirubicin, cisplatin and fluorouracil for gastric cancer: results of a randomized trial. Br J Cancer 80: 269-272.

20. Wagner AD, Unverzagt S, Grothe W, Kleber G, Grothey A, et al. (2005) Chemotherapy for advanced gastric cancer. Cochrane Database Syst Rev 3 : CD004064.

21. Cunningham D, Allum WH, Stenning SP, Thompson JN, Van de Velde CJ, et al. (2006) Perioperative chemotherapy versus surgery alone for resectable gastroesophageal Cancer. N Engl J Med 355: 11-20.

22. Bölke E, Peiper M, Budach W (2008) Capecitabine and Oxaliplatin for Advanced esophagogastric Cancer. N Engl J Med 358: 36-46.

23. Takahashi T, Saikawa $Y$, Kubota T, Akiba $Y$, Shigematsu N, et al. (2003) Histological complete response in a case of advanced gastric cancer treated by chemotherapy with S-1 plus low-dose cisplatin and radiation. Jpn J Clin Oncol 33: $584-588$ 